\title{
Imaginarios sociales y biopolítica en la escuela: la mujer como cuerpo del delito
}

\author{
SOCIAL IMAGINARY AND BIO-POLITICS IN SCHOOL: WOMEN AS THE BODY OF CRIME
}

Leticia Arancibia (leticia.arancibia@gmail.com) Escuela de Trabajo Social, Pontificia Universidad Católica de Valparaíso (Valparaíso, Chile)

Pamela Soto (pamela.soto.garcia@gmail.com) Instituto de Filosofía, Pontificia Universidad Católica de Valparaíso (Valparaíso, Chile)

Andrea González (andrea.gonvera@gmail.com) Escuela de Trabajo Social, Pontificia Universidad Católica de Valparaíso (Valparaíso, Chile)

\begin{abstract}
The article presents a theoretical discussion and sociological analysis about the tensions in the building of social sex/gender relationships that are at the basis of the exclusion of women within the political field. It shows contents in dispute in the production of politics, considering the weight that categories play in the relations at a global level and in the school, the attributions inside the system sex/gender, the significations in politics, and the modes in which it is subjectified, resisted and confront different logics to understand life and politics, considering the conceptual distinctions between Bíos and Zoé. This discussion allows the analysis of the imaginary institution within systematic difficulties and obstacles of political and legal kind during the post dictatorship in Chile, where based on arguments about the sex/gender system, the exclusion of women from the political field is established, limiting the development of politics that valorizes cultural diversity and human rights, accentuating discrimination and social exclusion. These shape the discussion over the modes in which the political field for women is configured, recovering the possibilities of conflict as an opening of that horizon.
\end{abstract}

Key words: social imaginary, conflict, biopolitics, school, sex/gender system.

\section{Resumen}

El artículo presenta una discusión teórica y análisis sociológico acerca de las tensiones en la construcción social de las relaciones sexo/género, que fundamentan la exclusión del campo político de las mujeres. Se distinguen los contenidos en disputa en la producción de la política, considerando el peso que tienen las categorías en juego en las relaciones a nivel global y en el espacio de la escuela, las atribuciones dentro del sistema sexo/género, las significaciones de la política, y los modos en que se subjetivan, se resisten y se confrontan diferentes lógicas para entender la vida y la política, teniendo como base las distinciones conceptuales entre Bios y Zoé. Esta discusión permite analizar la institución del imaginario en el marco de las dificultades sistemáticas y obstáculos de tipo político y legal durante la post dictadura en Chile, donde sobre la base de argumentos propios del sistema sexo/género, se establece la exclusión del campo político de las mujeres, limitando el desarrollo de políticas que pongan en valor la diversidad cultural y los derechos humanos, acentuando la discriminación y la exclusión social. Estos dan forma a la discusión sobre el modo 
en que se configura el campo de lo político para las mujeres, recuperando las posibilidades del conflicto como apertura de este horizonte.

Palabras clave: imaginarios sociales, conflicto, biopolítica, escuela, sistema sexo/género.

\section{Introducción}

La discusión acerca de las dificultades en la institución de la democracia requiere analizar los modos en que se construye el campo de lo político, considerando el peso de las categorías que operan para la exclusión e inclusión de las mujeres como ciudadanas.

Observando los conflictos en la escuela, se distingue que el cuerpo femenino aparece como componente de una exclusión que no es solo social, sino también política, la que se encuentra marcada por las relaciones sociales instituidas al interior del sistema sexo/género (Tahon 1999) en diversos espacios. Las posibilidades de explicación exceden lo situacional y requieren de la profundización en el análisis desde las categorías de la filosofía política, que nos permitan distinguir la discusión sobre los conceptos de política y biopolítica, para responder a la pregunta ¿cuáles son las limitaciones para el acceso al campo de lo político del cuerpo femenino? Asimismo, desde una discusión contemporánea, ¿qué perspectivas de inclusión política son posibles para estos cuerpos?, entendiendo su institución previa, así como las posibilidades que opera en su significación, "como un sitio que a la vez permite y limita la acción política" (Martínez 2015:333). En ese sentido, si el ingreso de las mujeres en el campo de lo político considera la inscripción de los cuerpos femeninos en las relaciones sociales que dan forma a la polis, ¿cuáles son las posibilidades de expresión para estos cuerpos en el Chile de la postdictadura?

Para la comprensión de la condición de exclusión que afecta a las mujeres, consideramos la reflexión acerca de los cuerpos femeninos en el campo de lo político en el Chile de la postdictadura, distinguiendo y analizando las formas que adquieren las relaciones sociales en la institución imaginaria de la sociedad, puesto que los conflictos que se evidencian en la micropolítica permiten una aproximación a la comprensión del modo como se configura el campo de lo político y los debates acerca de la democracia. De este modo, el vínculo entre subjetividad y política adquiere importancia desde la vivencia del sujeto y las relaciones que establece a partir de los modos de pensamiento que son condición de la dominación masculina.

Para responder a estas interrogantes, en primer lugar, se abordarán las implicancias de los contenidos en disputa en el proceso de subjetivación y construcción de la política, considerando el peso que tienen las categorías de bíos y zoé des de la filosofía clásica y contemporánea. A partir de estos conceptos se establece el cuerpo femenino como cuerpo del delito, es decir, como componente de una acusación elaborada en el contexto del Estado patriarcal. En segundo lugar, se analizará el campo de lo político a partir del conflicto como categoría de comprensión para subvertir el lugar de la mujer en los imaginarios sociales dominantes, y el modo como la institucionalidad se pliega ante estos mandatos. Se tomarán como ejemplos algunos de los conflictos que se generan en la escuela y los efectos que tienen sobre las modulaciones del cuerpo y la sexualidad en las niñas y las jóvenes, a fin de presentar el fuerte vínculo entre el modo en que se construyen los imaginarios sociales acerca de lo femenino y la forma en que opera la biopolítica en la sociedad chilena de postdictadura. 


\section{El cuerpo de las mujeres en el dispositivo disciplinario de la Escuela}

\subsection{La polis y las posibilidades de la política}

La construcción social del género se sostiene a partir de la exclusión del campo político de las mujeres, a través de diferentes dispositivos de control y disciplinamiento que pretende la estandarización de los cuerpos femeninos sobre la base de estereotipos atribuidos de acuerdo al sistema sexo/género. Las categorías para el análisis de los fenómenos de discriminación que viven las jóvenes en el espacio escolar y los modos en que enfrentan la construcción estereotipada del sexo, pueden encontrarse a partir de la discusión sobre la tensión que se establece entre la "nuda vida» y la "existencia política», que están marcadas por los conceptos de zôe y bíos que retomamos desde Giorgio Agamben (2003).

El filósofo italiano remite a la crítica de esta pareja categorial que instituye una inscripción de lo político desde una concepción teleológica, que excluye a la posición del cuerpo del campo de lo político otorgándole el carácter de nuda vida, la cual sería asimilable a la de un animal sin logos. Mientras que bíos determinaría el carácter propio del ser humano que vive en comunidad y es capaz de desarrollar un ejercicio político: "Hay política porque el hombre es el ser vivo que, en el lenguaje, separa la propia nuda vida y la opone a sí mismo, y, al mismo tiempo, se mantiene en relación con ella en una exclusión inclusiva" (Agamben 2003:18).

La discusión de exclusión e inclusión que toma Agamben tiene su correlato en la filosofía clásica, especialmente en el pensamiento de Aristóteles, quien al hacer alusión a la vida, considera que es solo en el mundo político, es decir en la polis, donde el ser humano puede desarrollar una buena vida, puesto que es en la comunidad política donde es posible el despliegue del "nivel más alto de autosuficiencia, que nació a causa de la vida, pero subsiste para el vivir bien" (Aristóteles 1988, Libro I, página 49). Pues solo en este plano de lo público el ser humano deja el ámbito de las necesidades, cotidianas y no cotidianas, para dar paso al despliegue de una vida autónoma y autárquica, por lo cual la zoé o aquello que se excluye, remite a la condición corporal de lo humano, debido a que es el cuerpo el que se encuentra afectado por las necesidades cotidianas y no-cotidianas de la vida.

Desde esta perspectiva, solo en la vida política el ser humano puede ser feliz (eudaimónico), por lo tanto su desarrollo estaría dado en la dimensión pública, y no en el ámbito privado, debido que esta esfera no permite el desarrollo de la dimensión política del sujeto.

Sin embargo, lo problemático es el significado del vivir con vistas al vivir bien. Estas teorías enfatizan que la vida política solo se articularía en este vivir bien. Pero, ¿la política surge solo cuando es buena vida?

Desde el punto de vista de la subjetivación que yace bajo esta afirmación de la vida, se establece simultáneamente una exclusión de la nuda vida del ser humano, con esto la dicotomía entre "vivir» y «vivir bien» genera una exclusión, puesto que la dimensión de la zoé quedaría afuera. Entonces, ¿cuál es la relación entre política y vida, si ésta se presenta como aquello que debe ser incluido por medio de una exclusión?

\subsection{El registro de la vida y la subjetividad}

Esta discusión acerca de la exclusión/inclusión, se levanta sobre la base del reconocimiento de la construcción del cuerpo como campo político, de modo de problematizar la dinámica social y cultural 
donde el cuerpo instala a las mujeres fuera del campo de lo político, en el que el disciplinamiento del cuerpo opera como uno de los procesos que deja a las mujeres fuera de este campo.

La reducción del campo político para la integración dentro del orden instituido, obedece a que no se les reconoce la capacidad de autonomía a las mujeres. La reproducción que deja siempre afuera a las mujeres connota necesidades sociales que no logran tener el estatuto de la política. Así ocurre con la familia y la aldea en el pensamiento aristotélico, las cuales, si bien dan cuenta de una vida en comunidad, estos modos de organización no son autosuficientes como la ciudad, restringiéndose al ámbito de las necesidades (Aristóteles 1988). De este modo, la familia y la aldea y quienes operan en su interior (mujeres, esclavos, o extranjeros, entre otros) quedan fuera de la política, negándoseles una posición como miembros de la ciudad. Esta negación no culmina en un dentro o fuera de lo político, sino que a su vez niega a un colectivo la condición mínima para ser parte de ello: "La razón por la cual el hombre es un ser social, más que cualquier abeja y cualquier animal gregario, es evidente: la naturaleza, como decimos, no hace nada en vano, y el hombre es el único animal que tiene palabra. Pues la voz es signo del dolor y del placer, y por eso la poseen también los demás animales, [...]. Pero la palabra es para manifestar lo conveniente y lo perjudicial, así como lo justo y lo injusto. Y esto es lo propio del hombre frente a los demás animales: poseer, él sólo, el sentido del bien y del mal, de lo justo y de lo injusto, y de los demás valores, y la participación comunitaria de estas cosas constituye la casa y la ciudad" (Aristóteles 1988, Libro I, página 51).

La producción de la política abre el campo de acción para todos y todas. La reivindicación de participación de la construcción social del género es parte de este campo, toda vez que a las mujeres se las mantiene ajenas al campo político, a partir de su negación en las dimensiones del lenguaje y la ética.

Esto opera en su constitución como sujeto, como una identidad reducida que se suscribe en una pura cuestión biológica o lógica de la producción (Tahon 1999), en tanto madre, en tanto cuerpo, y en tanto eslabón en la cadena de cuidado, sujetas a la familia, a la casa, dada su pertenencia al domesticus, espacio de dominio de otro (1).

Al negarse las dimensiones del lenguaje y la ética, se inscribe el cuerpo de la mujer en la vida como zoé. Existe un vínculo entre la reducción de la mujer a su cuerpo como zoé en cuanto: "cuerpo productivo biológico", capaz de producir otros seres humanos, ser madre, cuidar a los recién nacidos, y en tanto "cuerpo productivo industrial" (Tahon 1999), como parte de la división social del trabajo, donde realiza tareas definidas socialmente para su ubicación como cuidadoras y dentro de las tareas de reproducción de la mano de obra en el ámbito de lo privado. Ambas expresiones de este vínculo han sido objeto de procesos de tecnificación y racionalización dentro del capitalismo, manteniendo una lógica de dominio que deviene históricamente en estrategias de poder diferenciadas. Como indica Michel Foucault, existe en la sociedad contemporánea un particular principio de exclusión; no se trata ya de una prohibición, sino de una separación y un rechazo que se articula en base a ciertos dominios de saber que produciendo nuevos objetos, conceptos y técnicas, dan lugar a formas de subjetividad que naturalizan esa separación. Bajo el nombre de sociedad disciplinaria, se articula la forma de funcionamiento de cierto orden que articula formas de saber, relaciones de poder y tipos de subjetivaciones para su reproducción.

Si bien hay un vínculo directo entre vida y política, pues la vida humana tiene dos dimensiones (zoé y bíos), la zoé queda afuera estableciendo condiciones de control de lo político a través del bíos y lo vuelve por tanto teleológico. Este vínculo lo que hace es excluir el cuerpo o la pulsión. De este modo, bajo la forma de la vida racional, la biopolítica entrega una finalidad, se instituye como heteronomía. 
La construcción de un cuerpo biopolítico implicará, por tanto, el desarrollo de mecanismos de control de la buena vida, con una definición heterónoma de lo que sería esa buena vida.

En la definición de la zoé como vida nuda, y la vida política como la buena vida, tal oposición "es una implicación [...] de la nuda vida en la vida políticamente cualificada" (Agamben 2003:16). En la pregunta ¿por qué la política occidental se funda sobre la exclusión de la nuda vida?, se detectan maniobras de ocultamiento, sobre cuya exclusión se funda la biopolítica. Así, cuando la biopolítica coincide con la política y la negación de la inscripción en el cuerpo, la mera vida puede ser sacada de todo contexto, a un extremo tal que puede ser aniquilada sin que entre en la esfera de lo punible, del mismo modo como Arendt presenta en Eichmann à Jerusalem cómo opera la banalidad del mal, bajo la "desnaturalización del imperativo ético" (Revault d'Allonnes 2006:181).

Desde esta perspectiva, podemos situar el análisis en cómo la biopolítica ha instaurado un modelo de control sobre la población femenina, que en su ubicación estratégica fuera del campo de lo político, reduce su existencia a mera zoé, por la condición de necesidad y reproducción doméstica de la vida que comportaría.

\subsection{La mujer desde el margen. La producción política desde la resistencia de la zoé}

La expropiación de la mujer del campo de la buena vida -y con ello de lo político- se evidencia en los discursos y la dinámica que se construyen en la escuela secundaria, donde se observan las dificultades que enfrentan las jóvenes ante la primacía de la construcción de las relaciones bajo un imaginario de sexo/género, el cual, marcado por la obligatoriedad de la adscripción a una identidad, implica la imposición, que excluye, y establece el límite del campo de la constitución de las mujeres y niñas dentro de la construcción de la política.

En este sentido, siguiendo a Butler utilizamos la noción misma de "el cuerpo", "no como una superficie disponible que espera significación, sino como un conjunto de límites individuales y sociales que permanecen y adquieren significado políticamente" (Butler 2007:99).

Marie-Blanche Tahon desarrolla la discusión sobre la correspondencia y la distancia entre derechos sociales y derechos políticos en el caso de las mujeres, donde los procesos de lucha por sus derechos han seguido recorridos de reconocimiento que escinden lo social de lo político. En esta lógica, la construcción de las relaciones sociales implica relaciones entre los sexos, adquiriendo el sexo femenino una connotación social excluyente del reconocimiento explícito del campo político. Se lleva la ley al contrato entre partes individuales y a la cuestión patrimonial, en tanto reparto y dominio.

El cuerpo de las mujeres, se invisibiliza en su inscripción en el campo de lo político, quedando reducido a un desglose de funciones y normas. Con ello, aludimos a que la discusión no solo es un tema de derechos, sino de campo político, porque parte de las demandas que se ciernen como sobras y sombras de las reivindicaciones de género, en relación a los temas de interés general, aparecen desde el margen de la sociedad, para convertirse en cuestiones que quedan en el ámbito privado, y por ello fuera del campo político.

En efecto, cuando se habla de mujeres en la política y su vínculo con el campo de lo político, varias de esas discusiones se reducen a ley de cuotas y a la generación de medidas de "discriminación positiva" (2), donde lo que se hace es reconocer, pero al mismo tiempo asumir, bajo la forma de una "concesión a las minorías", 
esta exclusión. De este modo, pueden verse políticas que refuerzan la división sexual del trabajo y la discriminación, donde la crianza de los hijos es atribuida exclusivamente a las mujeres, o como ocurre en el caso chileno, donde se grava a las mujeres con un impuesto al útero en el ámbito laboral, previsional y de salud, sin que se reconozcan las discusiones respecto del alcance de la participación en diferentes espacios de construcción cultural y la contribución de niñas y mujeres en la realización de un proyecto civilizatorio diferente.

Desde esta perspectiva, la educación estaría resguardando que el estado de la cuestión no varíe en la situación de las mujeres. Y esto significa el despliegue de los dispositivos a través de los cuales se instituye la escuela como espacio de reproducción, como parte integrante de la dinámica que deja a las mujeres fuera de lo político.

Marie-Blanche Tahon formula la crítica a teóricos posmodernos que plantean "pensar más allá de las identidades", advirtiendo que las identidades opresivas o liberadoras siguen estando al centro de la lucha política en el mundo contemporáneo. Cuestionando la perspectiva multiculturalista neoliberal, señala que estos conflictos no se resuelven con talleres de capacitación sobre "manejo de la diversidad", sino visibilizando y afectando los problemas de redistribución material e injusticia que hacen de las diferencias, desigualdades. En este mismo registro, Amina Mama, enfatiza sobre la ilusión de la retórica culturalista que pretendería el reconocimiento sin redistribución, apelando a las lógicas de dominación presentes que quedan en evidencia desde los movimientos, los cuales desde una posición principalmente de resistencia, pueden acentuar la singularidad de esa lucha, y no abordar el trasfondo cultural y económico del problema de la exclusión y segregación de las mujeres del campo de lo político. Esto requiere distinguir las articulaciones entre la hegemonía presente y la historia a través de la cual se fue configurando esa hegemonía, que en el modo de producción actual cobra una forma particular de aproximación al problema.

\subsection{El disciplinamiento del cuerpo: el cuerpo del delito}

Algunas de las expresiones del problema de exclusión que produce el sistema sexo/género se observan en los conflictos presentes en el espacio escolar. Allí los actores connotan de manera diferenciada las situaciones y los elementos en juego en cada una de ellas.

Prestamos atención a algunos de los contenidos de la construcción social del género que aparecen como significativos desde los imaginarios, apareciendo ya sea como parte de los procesos de dominación y resistencia a la reproducción de un sistema de hegemonía patriarcal, a la vez que como sentidos que refuerzan o amplían la construcción política de la situación de la mujer en la sociedad actual.

Desde el discurso institucional de las escuelas, una de las fuentes principales de los conflictos estaría asociada a la disciplina (o la indisciplina) de los estudiantes. En términos generales, las relaciones entre profesores, profesoras y estudiantes aparece fuertemente marcadas por un afán de control de la disciplina en clases, en la medida que su transgresión representaría una limitación al desarrollo de su trabajo educativo en el aula. Pero el tipo de situaciones y los elementos que se ponen en juego aquí, varían según se trate de hombres o mujeres, estableciéndose las relaciones de poder que se organizan en las significaciones socio-simbólicas que definen el cómo "ser mujer" y cómo comportarse en el liceo conforme ese conjunto de representaciones y prácticas de las cuales esa institución se hace parte. 
La imagen de la escuela de señoritas opera para significar ese espacio exclusivo de formación, donde priman estereotipos y presionan por la reproducción de roles y formas tradicionales de la construcción de lo femenino (De Barbieri 1993). En este imaginario, los contenidos sobre la sexualidad son de carácter moralizante para las mujeres y se evita su discusión abierta.

La escuela propicia procesos de subjetivación en los que se considera un tipo ideal de mujer, sobre la base de cuya imagen se tiende a reproducir el estereotipo femenino, ya sea por el contenido de los discursos, como por las características atribuidas sobre la base de las cuales se permiten y legitiman las formas de control, apelando a una supuesta naturaleza que se instala desde el gesto y que territorializa el cuerpo.

En los discursos de profesores, profesoras y estudiantes, la regulación y la construcción del género están presentes en las significaciones imaginarias de la disciplina. Ello se observa en un énfasis explícito en la regulación de los comportamientos sexuales de las niñas y jóvenes en el espacio escolar, aludiendo estereotipos de género donde se le atribuyen características de agresividad a los hombres, mientras que se considera a las mujeres poseedoras de sensibilidad, lo que redundará en la división social del trabajo, en potencialidades esperadas para hombres en cuanto a sus capacidades de ser propositivos, arriesgados y competitivos, mientras que de las mujeres se esperará que se muestren pasivas, mesuradas y dóciles.

La indisciplina de los estudiantes vista por los profesores toma como pruebas el desorden, el lenguaje procaz, la falta de atención dentro de la sala de clases, pero en el caso de las niñas y las jóvenes, la indisciplina incorpora además como manifestación crítica el comportamiento relacionado con la construcción del género femenino y la condición sexual.

Las significaciones sobre la disciplina en clases en el caso de las niñas y mujeres se refiere al intento de regulación de los comportamientos sexuales buscando el control de la sexualidad de las estudiantes. En la escuela y en especial en el caso de establecimientos de mujeres, se plantea la doble exigencia de disciplinamiento del sistema sexo/género. Por una parte, el cuerpo está marcado por la normatividad de la castidad, pero por otra parte, y siendo condición paradójica, se desarrollan diferentes intentos por excluir la diversidad sexual, asumiendo la obligatoriedad de la heterosexualidad (Butler 2007).

La primacía de estereotipos y roles tradicionales femeninos en los hábitos cotidianos del patio, de la sala de clases en horas muertas, así como la elección de su orientación en las especialidades técnicoprofesionales, denotan el prisma bajo el cual las jóvenes viven, resisten o aceptan la construcción impuesta del género, donde la escuela opera como un lugar de reproducción social de las jerarquías que establece un modelo tradicional de relaciones entre hombres y mujeres.

El código de comportamiento en clases saca a la luz el establecimiento de cánones diferenciados de comportamiento para hombres y mujeres, donde los profesores utilizarían cánones más estrictos en el caso de las niñas y jóvenes, en tanto portan un cuerpo que produce otros seres (Tahon 1999). Su cuerpo individual es a la vez cuerpo social, que asegura la continuidad de la especie. A partir de la categorización del cruce entre cuerpo individual y cuerpo social en las jóvenes, se instala un doble conflicto. El primero consiste en que se entregan categorías biomédicas al cuerpo femenino, mientras que en un segundo registro, se marca el cuerpo femenino desde el cuidado y uso de su cuerpo que trasciende los límites de su propia vida, por lo cual los otros, al igual que ella, pudiesen controlar, dominar o intervenir en aquel cuerpo. 
La presencia del dispositivo disciplinario alcanza sofisticación, internándose en una subjetividad proyectada en el gesto cotidiano, que toma forma de biopolítica en tanto se inscribe en el cuerpo individual, que reduce a las mujeres a la manera de una anatomo-política. Pero que se extiende más allá del cuerpo individual y abarca hacia las políticas públicas, bajo el modo de una biopolítica de la especie, preocupada por el aseguramiento de la reproducción de la población. Debido a que a partir del cuerpo de la mujer no solo se aplica, utilizando terminología de Foucault, anatomo-política, sino biopolítica, en cuanto a partir de este cuerpo se intenta regular a toda la población femenina, lo que extrapola el problema desde el cuerpo de una mujer a toda la población: "Luego de la anatomo-política del cuerpo humano, introducida durante el siglo XVIII, vemos aparecer, a finales de éste, algo que ya no es esa anatomopolítica sino lo que yo llamaría una biopolítica de la especie humana" (Foucault 2000:220).

Esta moderna biopolítica se ocupará entonces de las tasas de nacimientos y muertes, la fecundidad de la población, las enfermedades endémicas, las enfermedades incapacitantes, etc. Las disciplinas tenían que ver con el individuo y su cuerpo, pero ahora ni siquiera se apuntará a la sociedad como tal, sino a la idea de población. De modo tal que el poder "ya no tiene que vérselas sólo con sujetos de derecho[...], sino con seres vivos, y el dominio que pueda ejercer sobre ellos deberá colocarse en el nivel de la vida misma" (Foucault 1996:135).

La biopolítica tiene que ver entonces con la población como problema político, como un nuevo cuerpo "un cuerpo múltiple, cuerpo de muchas cabezas, sino infinito, al menos necesariamente innumerable" (Foucault 2000:222).

Este registro de extrapolación, desde el cuerpo individual a la biopolítica de la población, es posible constatarlo a partir de las brechas que se establecen entre el discurso adulto tradicional, de profesores y directivos, y el discurso crítico de algunas de las estudiantes, quienes despliegan el cuestionamiento a la escuela y a una cultura que las deja en posición de subordinación dentro de un sistema político y económico que las segrega por ser mujeres, jóvenes y pobres, estableciéndose el campo donde se desarrolla un imaginario radical. Este imaginario se instituye desde las significaciones de las estudiantes sobre su sexualidad, el reconocimiento de capacidades plenas y la demanda de una posición distinta dentro de la sociedad.

\section{El registro del conflicto como apertura del campo de lo político}

Luego de examinar el modo en que es inscrito el cuerpo de las mujeres en el dispositivo disciplinario de la escuela, es preciso dar el paso desde el registro de la subjetividad a la política, del campo del derecho al campo de lo político.

Al observar las tensiones en la construcción social del género, que aparece marcada por la obligatoriedad de la adscripción a un género y a sus diferentes modos de expresión, que excluyen la constitución de las mujeres y las niñas de la construcción de un campo político, se ha identificado el movimiento a través del cual se establecen mecanismos de subjetivación política, que como primera condición debe reconocer una identidad. Esta identidad, en el mundo moderno, se erige desde la exigencia del Estado liberal: tener un nombre y una adscripción a un género.

Butler destaca a partir de Foucault que "las identidades son formadas en el interior de dispositivos políticos contemporáneos de ciertas exigencias del Estado liberal. Estas exigencias, suponen que la afirmación y la reivindicación de derechos no pueden más que emanar de una identidad singular que ha sido invocada. 
Por ello, mientras más específicas son las identidades, más se reducen a esa especificidad" (Butler 2002:158).

Este fenómeno corresponde al movimiento por el cual un aparato jurídico produce el campo de sujetos políticos: "En la medida que, según Foucault, el aparato disciplinario del Estado opera a través de la producción totalizante de individuos y donde esta totalización extiende la jurisdicción del Estado (transformando, precisamente los individuos en sujetos del Estado)" (Butler 2002:158).

En esta discusión, los sujetos no lograrían su condición sino a condición de ser para y desde el Estado, por lo tanto el poder del individuo se limitaría a la reivindicación y apelación a un Estado que constituye la categoría de sujetos políticos en tanto demandantes. Esto pone en cuestión el lugar que damos a la igualdad, estableciendo una aporía entre la igualdad de origen, o la aspiración a la igualdad: "una política de la identidad, como dispositivo del poder jurídico, es producida por un Estado capaz de otorgar reconocimiento y derechos solamente a sujetos totalizados por la particularidad que constituye su estatuto de demandantes" (Butler 2002:158). Por esto, la reivindicación no puede ser sólo por derechos, "sino por una constitución radical de la subjetividad formada en y contra la hegemonía histórica del sujeto jurídico" (Butler 2002:158).

Butler cita a Foucault estableciendo que aquello significa que "una lucha emancipadora busca algo más que la inclusión dentro del orden jurídico, pues tanto en la resistencia y la crítica, a la vez que en su aceptación, se impone una cierta sujeción a ese orden jurídico. Esta «doble sujeción» política, que son [a la vez] la individualización y la totalización simultáneas de las estructuras de poder moderna" (Butler 2002:159). Eso exige que se desarrolle una lectura que ayude a entender ese orden desde la resistencia al cuerpo disciplinario.

Desde esta perspectiva, la formación de la identidad del sujeto se daría bajo la condición de asumir la respuesta a una ley, de endosar una culpabilidad fuera del yo. Esto implica que quien se torna hacia la ley, desarrolla un acto condicionado, "a la vez por la voz de la ley y la capacidad de reacción de quien es interpelado por la ley" (Butler 2002:166). Tal como la lógica de la conciencia en Althusser y la complicidad que condiciona la propia crítica exigiría "una voluntad de no ser - una des-subjetivación crítica- a fin de mostrar que la ley es menos potente que lo que aparenta" (Butler 2002:197). Sin embargo, esto representa una ilusión de la autonomía del sujeto que se desvanece ante el mandato de la norma que se extiende más allá de lo que advierte el propio sujeto: “¿Cómo un deseo es explotado no sólo por uno, sino por varios órdenes de leyes, deseo que nos hace ceder a la subordinación para mantener nuestro sentimiento de 'ser' social?" (Butler 2002:197).

Butler considera los planteamientos de Althusser respecto del sometimiento como aceptación y ésta a su vez, como orientación hacia la ley: "La orientación hacia la ley es una orientación, un retorno contra sí que constituye un movimiento de conciencia. Pero el reflejo de la conciencia ¿no paraliza la crítica de la ley al mismo tiempo que forma la relación no crítica del sujeto a la ley en tanto que condición de sujeción? El destinatario está constreñido de volver hacia la ley antes de tener la menor posibilidad de interrogarse: ¿quién habla? ¿Por qué debería voltear? ¿Por qué debería aceptar los términos en los cuales soy llamado?" (Butler 2002:167).

A partir de esta consideración para evitar la reproducción, sería el conflicto la situación que performaría lo político, evitando la naturalización y el anquilosamiento en el cual puede caer la institución de una sociedad dada. Chantal Mouffe señala una distinción entre lo "político» y la "política», que permite 
recuperar el conflicto desde la dimensión de antagonismo: "concibo 'lo político', como la dimensión de antagonismo que considero constitutiva de las sociedades humanas, mientras que entiendo a 'la política' como el conjunto de prácticas e instituciones a través de las cuales se crea un determinado orden, organizando la coexistencia humana en el contexto de la conflictividad derivada de lo político" (Mouffe 2011:16).

Es preciso recuperar y poner al centro el conflicto como elemento central de lo político, que da forma y vuelve posible lo social. De ese modo es como se instituye la apertura, más allá de la política instituida por el orden estatal, que obliga a los sujetos a una identidad ante la ley. El ser para el Estado limita las posibilidades de creación. La sujeción al cuerpo alejaría del campo del conflicto, sin reconocer que esa sujeción es la base del conflicto que implica la discriminación, enajenación del campo de lo político.

Al ver el conflicto como creación (ex-nihilo), como resistencia (en tanto búsqueda de la fisura, del «nicho» que permitiría pervivencia) y la contradicción (las relaciones de oposición, la visión de opuestos binarios, excluyentes) que permite distinguir las formas que adquieren las relaciones superando un biologismo homeostático, como si fuera una sucesión de hechos encadenados desde la determinación de la adaptación.

Y el imaginario del Leviatán, el Estado como administración de sujetos en Hobbes, en tanto cesión de derechos, y campo de dominio del poder sobre los seres humanos, considerando la reelaboración del Estado en el marco capitalista neoliberal.

¿Cuáles son las lógicas de dominación que llevan (que portan los sujetos) sin darse cuenta? ¿Cuál es la segunda naturaleza que se reconoce como primera? ¿Quién soy yo para darme vuelta ante la ley? ¿Por qué debería voltear ante el llamado de la ley? La reducción de la mujer al campo de lo doméstico implica que siempre está sujeta al dominio, siempre voltea ante la ley.

La tragedia integra estas diferentes expresiones, cuando el sujeto logra ver su pasado y su futuro simultáneamente- cuando advierte las lógicas de dominación. La contradicción se erige en la visión de integración en la síntesis (tesis y antítesis, asumiendo la historia) o la creación ex-nihilo (autopoiesis) que crea algo totalmente nuevo más allá de la construcción cultural y política pasada.

\subsection{Discusión hacia la ampliación del logos de las mujeres}

Uno de los aspectos que resultan indispensables en el análisis de los dispositivos que permiten la instalación de discursos y significaciones que legitiman la dominación en un sistema sexo-género, nos lleva a examinar la unidad de la violencia y la escritura que se expresa en la hegemonía del orden patriarcal, que impone una cierta legitimidad o ilegitimidad de los saberes: "El sistema de signos, que el logos sea en principio una huella y que esta huella sea el recurso principal del lenguaje y la escritura, significa que el logos no es una creación, sino la traza, la marca de una dominación, que se reproduce a través suya" (Derrida 1962:126).

Desde el logos moderno, se da el cuestionamiento al sujeto trascendental. La verdad es la representación de la realidad del sujeto, representación no válida de la realidad.

Recuperamos la afirmación de Derrida en relación como el falogocentrismo integra la violencia en la escritura, donde el logos es entendido como capacidad de dominación de la realidad. En una línea similar, 
pero desde el psicoanálisis, Eugène Enríquez (1983) analiza la institución de la violencia en el lenguaje luego del asesinato del padre por parte de la horda primitiva, la cual en el proceso de institución del Estado recordará a los hijos ese acto inicial de violencia que funda el lenguaje y la construcción simbólica de la realidad.

En esta operación, la marca de una dominación originaria establecería un abismo alrededor de lo simbolizable sobre y desde la mujer. Se fija un imaginario donde la salida de ese espacio ya simbolizado, el paso a la creación, es vista como el salto al vacío. Dar un paso adelante significaría la caída en el abismo de la insignificancia, en el caso de las mujeres significa la aceptación de la imprevisibilidad potencial de su capacidad de acción, de agenciamiento, en esto, "Ios antagonismos que ella comporta no son recuperables en el horizonte tradicional de lo político" (Guattari 1989:160). Pero habría impactado en el nivel de las conciencias, de los deseos y de los comportamientos.

Visto desde el punto de vista filosófico, la carencia del logos se reduce a la capacidad de la razón, que en la época moderna se configura como una razón antropocéntrica. El logos clásico griego, refiere una cuestión polisemántica, donde se puede encontrar una doble acepción, como forma de concepción, razón, ciencia o episteme. Mientras que, en el mundo moderno, es más cercano de la razón, pero esta razón moderna, respaldada, legitimada o "escoltada» por la razón producida por el conocimiento científico. Es por lo tanto una razón cuantitativa, taxonómica, que señala el tiempo continuo, una sincronía y orden general de las cosas. Con este movimiento, la razón referirá al pensamiento dominante, aquel que definirá el orden social y las demás relaciones que se desprenden a partir de esa matriz.

Estableciendo una diferencia entre el logos clásico que refiere a la razón y el logos moderno que refiere a la legitimidad del conocimiento. No obstante, la razón en general refiere al pensamiento dominante.

Derrida cuando habla del falogocentrismo señala el paradigma de un logos dominador: "de un discurso al otro, la diferencia no puede ser aquí sino un modo de habitar al interior de una 'conceptualidad' prometida o ya sometida al mal estado. En ella y ya sin ella, habría que tratar de recuperar la unidad del gesto y la palabra, del cuerpo y del lenguaje, del instrumento y el pensamiento antes que se articule la originalidad del uno y el otro y sin que esta unidad profunda de lugar a la confusión. No hay que confundir estas significaciones originales en la órbita del sistema donde ellas se oponen. Pero habría que, al pensar en la historia del sistema, exceder en alguna parte, de manera exorbitante, sentido y valor" (Derrida 1962:126).

Esta sujeción a un logos de dominio se confronta a la idea del logos amplio, donde la producción no sea el elemento articulador que reduce la vida una pura razón instrumental. El viraje al sujeto como una de las vías reflexivas, exige distinguir la producción subjetiva en el imaginario cuando se trata de comprender las significaciones, procesos y acciones a las que da forma el conflicto.

\subsection{La producción de la matriz heterosexual y la producción como adquisición de la subjetividad}

En la escuela, la diferencia de las jóvenes respecto del sentido de una moral estricta impuesta por la sociedad a las relaciones entre los géneros, es vista por la institución como una amenaza: "El género es la estilización repetida del cuerpo, una sucesión de acciones repetidas -dentro de un marco regulador muy estricto- que se inmoviliza con el tiempo para crear la apariencia de sustancia, de una especie natural de ser" (Butler 2007:98). 
Particularmente en liceos de mujeres, el lesbianismo suele ser visto como conflicto principal por algunos de sus actores. Bajo una lógica del prestigio, la institución impone la sanción social a las estudiantes, asociando la imagen que sentencia a una mala vida futura y el riesgo de la pérdida de su capacidad de reproducción como madre, como nuda vida o zoé, donde se acabaría el futuro.

Sin embargo, no obstante el peso de la sanción social, la práctica sexual lésbica se contextualiza en sí misma ya como mecanismo de resistencia, a lo que Butler ha definido como parte de un dispositivo disciplinario que se impone en la escuela asociado a contenidos donde, no solamente se exige el cumplimiento de roles tradicionales, sino la "heterosexualidad obligatoria" (Butler 2007).

El ejercicio de una sexualidad lésbica, se considerará "disidente» toda vez que deja en cierto "vacío de poder» a las estrategias de control utilizadas por la institución, orientadas a mujeres idealmente heterosexuales. Las jóvenes que aparecen fuera de los cánones normativos ponen en entredicho las estrategias de control tradicionales destinadas a dar respuesta a la necesidad de producir "mujeres", deslegitimando la lesbofobia.

El conflicto se genera al nivel de las categorías utilizadas para nombrarlo, éstas le dan forma y contenido. Éstas operan sobre la base de exclusiones, agrupaciones y asociaciones en la construcción del sentido. Una pregunta sobre este orden del discurso que exige la consideración de: “¿Cómo construye el lenguaje las categorías de sexo?" (Butler 2007:39) y que metaforizan el ser hombre, ser mujer, como dominio donde confluyen la "heterosexualidad obligatoria» y el "falogocentrismo». "¿Cuál es el vínculo entre género y sexualidad?" (Butler 2007:13) y ¿dónde están sus puntos de ruptura?

En el caso de los establecimientos educacionales las categorías de género y sexualidad se articulan en el discurso a partir de la imposición de una sexualidad única a las mujeres, no se distingue necesariamente de la primacía del discurso falogocentrista, que establece la hegemonía del hombre y del género masculino.

\subsection{Sexo, género y patriarcado}

En medio de la discusión respecto de qué concepto utilizar, ya sea el de género como propone Teresita de Barbieri, o el de sexo propuesto por Marie-Blanche Tahon, así como las relaciones sociales de sexo desde Helena Hirata, preferimos referirnos al sistema sexo/género para captar el proceso a través del cual se impone el poder de la visión de univocidad del sexo, que le asignaría la coherencia interna del género y el marco binario para sexo y género, que serán para Butler "ficciones reguladoras que refuerzan y naturalizan los regímenes de poder convergentes de la opresión masculina y heterosexista" (Butler 2007:99).

La forma en que lo leemos es desde la consideración de las relaciones de sexo como relaciones de poder, tal como refiere Michel Foucault, Marie-José Nadal, Marie-Blanche Tahon y otros autores. Por lo tanto es preciso considerar el sexo/género como un sistema de relaciones dialécticas, de luchas y enfrentamientos, en permanente conflicto, tácito o explícito para quien lo experimenta: "Así, el sexo/género deviene una categoría movible, en perpetua construcción / deconstrucción / reconstrucción, en el seno de la cual el contorno y las fronteras de las categorías de sexo se redefinen perpetuamente. En este nivel, los momentos de cambios sociales, los momentos de conflictos, en el seno de los cuales las normas del género son cuestionadas, donde los actores, voluntariamente o no, borran las fronteras entre los géneros y manipulan las definiciones de lo masculino y lo femenino, son momentos importantes puesto que dejan en evidencia cómo la dualidad se mantiene, pese a los cambios" (Nadal 1999:16). 
Esto permite ir más allá de todo espejismo mistificador por una parte, que se pliega a las definiciones naturalistas del sexo, o bien las lecturas que establecen una relación binaria no dialéctica que no admite la fisura o la resistencia. Por lo tanto, es preciso "construir objetos de investigación que permitan dar cuenta de cada una de las dos categorías de sexo y trabajar a la vez en el corazón y en los límites de esas categorías, sobre la bicategorización misma" (Daune-Richard y Devreux 1992:20), reconociendo el orden patriarcal en el cual se dan las relaciones sociales. En palabras de Butler: "La organización de la ley del patriarcado como una estructura represiva y reguladora también exige ser replanteada desde esta perspectiva crítica" (Butler 2007:102). En la medida que se designa la unidad de cualquier género ésta necesitaría de una sexualidad estable y de oposición que la configure.

En la teoría feminista, "uno habla como mujer aunque el sujeto mujer no es una esencia monolítica definida de una vez y para siempre, sino que es más bien el sitio de un conjunto de experiencias múltiples, complejas y potencialmente contradictorias, definido por variables que se superponen, tales como la clase, la raza, la edad, el estilo de vida, la preferencia sexual y otras" (Braidotti 2000:35), donde la diferencia sexual deviene como proyecto político nómade.

Pensamiento radicalmente materialista, en cuanto pone el acento en condiciones concretas "situadas" que estructuran la subjetividad, pero también le dan un matiz novedoso a la noción clásica de materialismo porque redefine la subjetividad femenina como una red progresiva de formaciones de poder simultáneas. Para Braidotti en el centro de la redefinición de género, en tanto técnica de sí mismo (3) apunta a una política de la subjetividad. Desde un doble sentido, por una parte, "en cuanto se refiere a la constitución de identidades, como a la adquisición de subjetividad, entendidas como formas de autorización o autoridad para ejercer ciertas prácticas. El termino francés assujettissement representa bien ambos niveles de este proceso de subjetivación: es un proceso material y también semiótico que define al sujeto mediante una cantidad de variables reguladoras: sexo, raza, edad, etc. [que a su vez se utilizan como efecto de discriminación]. La adquisición de la subjetividad es por lo tanto un proceso de prácticas materiales (institucionales) y discursivas (simbólicas) cuyo objetivo es positivo -porque da lugar a formas de empoderamiento (empowerment) y regulación- porque estas formas son el lugar de limitaciones y disciplinamiento" (Braidotti 2000:115).

Esta sujeción de las jóvenes en la escuela se da en primer término en la condición de mujer, luego en la situación de pobreza como estudiantes de liceos vulnerables, que se cierne como el estigma que las expone en el espacio local a la asignación de atributos que las desacreditan y que les imponen la discriminación como condición de vida.

Por otra parte, las formas de sujeción de las niñas y mujeres a las demandas del sistema sexo/género se expresan tanto en la reiteración del gesto de la sumisión en el contexto de violencia explícita, como a aquel gesto a través del cual se cuestiona su propio saber. Configurándose un campo que genera la impresión y el deseo de la inclusión desde la exclusión, donde el mal menor es el único bien que se les ofrece y que merecerían en contextos de pobreza y necesidad. El deseo es reemplazado por la necesidad y lleva el signo de una nueva sujeción, que se marca por la dependencia del deseo del otro, como si fuera su propio deseo. Con esto no sería posible destituir la condición de lo femenino, de la necesidad, del cuerpo o de la dependencia, debido a que en este punto reaparecen los mismos argumentos que exponíamos en el apartado que remitía al mundo clásico. 
Esta situación se sostiene también por el peso de las significaciones dominantes en el ámbito político. En particular podemos señalar las sistemáticas dificultades, y los múltiples obstáculos, de tipo legal y político, que se han levantado para impedir el abordaje de políticas sobre sexualidad en el espacio escolar. En la educación, si se trata de sociedades autónomas, estas tenderán a producir la emancipación y la conciencia de su propia institución, sin embargo si esta sociedad oculta en el imaginario su propia institución, niega su capacidad de transformación y allí los sujetos explican, se conforman o naturalizan las diferentes dominaciones ordinarias y generales.

Este rasgo de heteronomía se manifiesta en la construcción simbólica del género, en la naturalización de la dominación masculina, en la obligación de la heterosexualidad, en la negación de los derechos de las estudiantes, demostrando que la escuela sería sobretodo un lugar de transmisión, de tensión, de adaptación, contestación y resistencia ante contenidos signados bajo la marca de la construcción social del sistema sexo/género.

Las disputas de sentido sobre los contenidos que se quiere entregar a los "recién llegados" (Arendt 2003:286), nos exige distinguir los esquemas de pensamiento y creencias más o menos articulados que establecen categorías, operaciones de distinción y exclusión, jerarquías y elementos tachados, donde se expresa el tipo de legibilidad que alcanzan las relaciones sociales en esa sociedad en particular. En un contexto de alta complejidad, hay elementos propios de la relación educativa que se desdibujan, algunas de ellas se hacen eco de las transformaciones culturales que generan cambios en las relaciones entre adultos y niños, donde se van desdibujando elementos de la autoridad adulta.

En lo que concierne las relaciones de género y las formas de control y disciplinamiento de las niñas y las jóvenes que dan énfasis en el control de la sexualidad, a través de procesos a veces explícitos de disciplinamiento, a veces sometidos a sofisticadas técnicas de control de la institución escolar, no están ajenas a la cultura y política global. Esto se corresponde con el fenómeno observado durante la transición política en Chile, en la trayectoria que han tenido las políticas de sexualidad, con la oposición sistemática de algunos actores sociales y políticos.

De este modo, son también las regulaciones educacionales, la experiencia de las jóvenes y los profesores y profesoras, la cultura de la escuela y la organización de la misma que intenta, ya sea aislar, acoger, enfrentar, asumir, resistir o producir una cierta educación. Un ejemplo de la persistencia de estas técnicas es experimentada, actualmente, a partir de la implementación de otros indicadores de calidad educativa, por parte del Ministerio de Educación del país, que reduce el problema de la equidad de género al logro equitativo de resultados en pruebas estandarizadas de lectura y matemática, sin considerar la dinámica singular que se observa en la micropolítica de la escuela, y el marco de comprensión y acción que se establece entre los actores que allí concurren, reconociendo la escuela como espacio público, donde se producen sentidos y significaciones imaginarias sociales que la comunidad ha creado, otorgando a partir de ello las posibilidades de acceso al magma.

\subsection{Imaginario autoritario y conflicto en la construcción del sistema sexo/género en la escuela}

El imaginario demuestra su eficacia en que este no es simbolizable, sino a través de la mediación de otros componentes. Según Butler, "el imaginario significa la imposibilidad de la constitución discursiva, es decir simbólica, de la identidad" (2002:153). Esto podemos verlo en mecanismos psíquicos como la forclusión, que implicaría la exclusión de la conciencia de algo que ha debido olvidarse, cuya existencia amenazaría la pervivencia y la continuidad del sujeto. 
La expectativa respecto del comportamiento de las niñas y jóvenes es la de una actitud pasiva, de menos "desorden» que los hombres y hay una baja valoración de sus argumentos. El temor a las represalias por la crítica, la defensa o simplemente la diferencia sexual, en algunas estudiantes opera como un elemento que inhibe la expresión de diferencias, pues al tratarse de la sexualidad, adquiere la connotación de transgresión grave, que los y las sujetos aceptan no sin dolor, naturalizando la imposición del sistema sexo/género, y la rigidez y homogeneización de los sujetos de la educación. El autoritarismo asociado pone el acento en aspectos disciplinarios que los sujetos deben obedecer o simplemente creer para la mantención de las relaciones consideradas «normales» sobre la base de las cuales se aseguraría la continuidad de una determinada civilización, raza, grupo o comunidad.

Se impone además la ilusión de armonía familiar o doméstica en la escuela que se debería desplegar sin mácula de conflicto, articulándose o dando expresión a procesos más globales en la sociedad chilena. De este modo, las disputas del imaginario sobre la sexualidad en la regulación educacional aparecen tras la ley no escrita, pero impuesta bajo la repetición de la obligación.

En el imaginario, no sería necesario que la norma esté escrita pues ya está impresa en las relaciones. El marco jurídico y procedimental supera de sobremanera el concepto de democracia participativa. Por más que exista en la nueva ley de convivencia la intención de encarnar los principios democráticos, participativos, informados y transparentes, se hace necesario no solo manifestarlo en el papel, sino que también implementarlo en un contexto general, asumiendo que los enclaves autoritarios deben desaparecer tanto desde un punto de vista procedimental como en el imaginario de la comunidad educacional.

En este registro, opera una suerte de autoanulación de los sujetos, donde los agentes ya no solo serán la escuela y los profesores, sino la familia (padres), la religión, la visión impuesta de lo normal, el peligro y la (falta de) madurez. Por otra parte, la meritocracia como factor de inclusión/exclusión que combina no solo atributos, sino condiciones estructurales que reproducen las posiciones y las jerarquías sobre la base de capitales, recursos y flujo de relación: los que merecen (estudiar, participar, movilizarse, tener una opción sexual).

Si consideramos que el conflicto en la sociedad refiere las tensiones estructurales, no solo situacionales que se generan en ella, el conflicto revela dinámicas sociales más profundas. Aquí se expresa el vínculo entre la dinámica de la escuela y la dinámica socio-política chilena de la postdictadura donde "se eluden conflictos que amenacen la estabilidad de una vida cotidiana sin perturbaciones" (Lira et.al. 2001:194). Si este argumento cobra vigencia cada vez que la verdad se hace conflictiva, se instituye una legitimidad de la negación, evitando el reconocimiento de los conflictos, perpetuándolos, y evidenciando las dificultades de cambio y superación de la "fragilidad del imaginario democrático" (Lechner 2002:114).

\section{Conclusiones}

A través de esta discusión podemos observar que la instalación de la escuela, más que como un espacio de lo político, donde se encontrarían procesos heterogéneos (de control y emancipación), aparece como policía, en tanto organiza posiciones y lugares donde toman parte los sujetos, bajo una mirada funcional que apoyado por la modalidad gubernamental asegura su reducción y acotamiento.

Con ello se limita la dimensión del conflicto, a la vez que la libertad, la cual como nostalgia de la luz rememora una pérdida. Pero a la vez aparece la crítica ante una conceptualización que la restringe a ese 
engranaje funcional que Jacques Rancière describe bajo la definición de policía, la cual bajo una totalización, desplaza y distribuye, ubicando cada cosa en su lugar, ejercitando y poniendo a punto dispositivos de control y disciplinamiento sobre la base de la repetición y la generalización.

Como biopolítica se inscribe en el disciplinamiento del cuerpo de las mujeres, que se vive como tragedia, con miras a la continuidad y persistencia de la efectividad de los dispositivos de control que operarán en el futuro para la acción de las mujeres (niñas, jóvenes y adultas) en la escuela y otros espacios. Pero también la política implica el devenir de los procesos gubernamentales y sus formas de relación con los procesos de emancipación. Utilizamos la distinción de Rancière (1998) entre los términos política y policía, pero apuntamos al campo de relaciones: territorio, dominio y poder. La emancipación como el espacio en que se comparte una igualdad de base que exige que todos jueguen el mismo juego.

La política que refiere a los derechos, que llega a dar vigencia legal a las relaciones en lo histórico-social y el nivel representacional del campo, establece al mismo tiempo un espacio de resistencia o contradicción, pero no alcanzaría al nivel de la creación de nuevas significaciones imaginarias sociales, donde alcance a tener visibilidad y se instituya otra forma posible de relaciones. Luego, "el proyecto de una sociedad autónoma pierde todo su sentido si no es al mismo tiempo el proyecto que apunta a hacer surgir individuos autónomos y recíprocamente" (Castoriadis 1990:183).

Una mayor participación de las mujeres en la política y la transformación de las actuales formas, implica cuestionar la condición de mujer resumida al binomio sexo/género, imperativo que determinaría a la mujer como el cuerpo del delito, y que se reproduce a través de las sutiles formas en que opera la leymicropolítica-, que se reconoce y se legitima, sin haber cuestionado el fundamento de la discriminación que desplaza a las mujeres fuera de la política.

La diferencia entre el acto de la libertad y la igualdad se da en el plano performativo indeterminado, desde las diferentes estrategias que despliegan para su realización, demostrando la marca de la brecha y la fisura. Es aquí donde se distingue que el conflicto permite el acceso de las mujeres al campo de lo político: "Reclamar el ejercicio de la libertad que solo corresponde a la ciudadanía es hacer ejercicio de esa libertad en forma incipiente, comienza por apropiarse de aquello que pide. Hay que entender que ese acto público pone en escena la libertad que reclama, afirmando lo que todavía no está allí. Hay una diferencia entre el acto y la libertad o la igualdad, que es el objeto, la meta que se está exigiendo. No es que todo se cumpla a través del lenguaje. No, no se trata de decir que soy libre y entonces mi enunciado performativo me vuelve una persona libre. No. Pero exigir libertad es comenzar a hacer ejercicio de ella, y pedir por su legitimación es anunciar la brecha que hay entre su ejercicio y su realización, inscribiéndolos en el discurso público de modo 'tal que la brecha se vuelva visible y pueda ser movilizante' " (Butler y Spivak 2009:91).

Por lo tanto, es en el plano profundo de la articulación de la forma en que esa vida singular disputa las relaciones, reconociendo el conflicto y la acción que moldea esa cultura a la cual está sujeta, que en lo histórico-social y la psiquis, se instituye la dinámica donde se problematiza y se cuestiona aquello que se había venido naturalizando e inscribiendo en el cuerpo y el imaginario del sexo/género femenino en la escuela, el cual bajo la configuración del cuerpo del delito da prueba de esta tensión.

\section{Patrocinio}

Se agradece a Fondecyt por el apoyo a la realización de la investigación $\mathrm{N}^{\circ} 11110328$, de Leticia Arancibia Martínez, así como también a la Pontificia Universidad Católica de Valparaíso por el 
financiamiento del Proyecto PIA Nº37.465 de la misma autora, en asociación con los investigadores Pamela Soto García (PUCV), Marie Verhoeven (Université Catholique de Louvain) y Abraham Franssen (Université de Saint Louis Bruxelles).

\section{Notas}

(1) En la raíz latina vemos que domesticus significa particular, desde allí se extiende hacia domesticarum, implicando la particularidad de lo que acontece en el espacio del domus, que significa casa, morada, refugio, nido, puerta del templo, privado, personal, interno, establo, redil. Cabe destacar que la raíz latina de domus corresponde a la misma raíz de dominio. En el mundo griego la casa comprendía la morada, la familia, el linaje, señalando con esto el dominio sobre su casa, mujer y esclavos.

(2) Puede verse en las directivas de la Unión Europea, que señalan leyes de cuotas tendientes a acercarse a la participación igualitaria en cargos de representación política, en el trabajo y más recientemente en los cargos directivos de las empresas connotando su participación de las decisiones en el ámbito económico (La stratégie de la commission européenne pour l'égalité entre les femmes et les hommes, 2010-2015). En América Latina se observa solo en algunos países la aplicación de leyes de cuota tendientes a asegurar igualdad de participación y representación de las mujeres en el ámbito de la política y la economía. Uno de estos casos es la Ley 581 del 2000 del Congreso de Colombia que asegura participación de las mujeres en cargos de representación política, así como en Uruguay la Ley 18476 de participación equitativa de ambos sexos en la integración de los partidos políticos y órganos electivos nacionales y departamentales del poder legislativo.

(3) En referencias al concepto foucaultiano de "técnicas del sí mismo", para expresar los fundamentos materiales de su visión del sujeto y, lo que es más importante, de los modos en que funciona el género, como una variable que estructura la subjetividad.

\section{Bibliografía}

Agamben, G. 2003. Homo sacer. El poder soberano y la nuda vida. Valencia: Pre-textos.

Arendt, H. 2003. Entre el pasado y el presente. Barcelona: Península.

Aristóteles. 1988. La política. Madrid: Gredos.

Braidotti, R. 2000. Sujetos nómades. Buenos Aires: Paidós.

Butler, J. 2002. La vie psychique du pouvoir. Paris: Éditions Leo Scheer.

Butler, J. 2007. El género en disputa. El feminismo y la subversión de la identidad. Barcelona: Paidós.

Butler, J. y Spivak, G. 2009. ¿Quién le canta al estado-nación? Lenguaje, política, pertenencia. Buenos Aires: Paidós.

Castoriadis, C. 1990. Le monde morcelé. Paris: Seuil.

Daune-Richard, A-M. y Devreux, A-M. 1992. Rapports sociaux de sexe et conceptualisation sociologique. Recherches féministes 5(2): 7-30. doi: 10.7202/057697ar

De Barbieri, T. 1993. Sobre la categoría de género. Una Introducción teórica metodológica. Debates en Sociología 18: 145-169.

Derrida, J. 1962. De la grammatologie. Paris: Les éditions de Minuit.

Enríquez, E. 1983. De la horde à l'État. Essai de psychanalyse du lien social. Paris: Gallimard. 
Foucault, M. 1996. Historia de la sexualidad. Vol. 1. La voluntad de saber. Madrid: Siglo XXI.

Foucault, M. 2000. Defender la sociedad. Buenos Aires: Fondo de Cultura Económica.

Guattari, F. 1989. Cartografías del deseo. Santiago: Santiago Zegers.

Lechner, N. 2002. Las sombras del mañana. La dimensión subjetiva de la política. Santiago: Ediciones LOM.

Lira, E; Loveman, B; Mifsud, T. y Salvat, P. 2001. Historia, política y ética de la verdad en Chile. Reflexiones sobre la paz social y la impunidad. Santiago: Ediciones LOM.

Martínez, A. 2015. La tensión entre materialidad y discurso: la mirada de Judith Butler sobre el cuerpo. Cinta moebio 54: 325-335. doi: 10.4067/S0717-554X2015000300009

Mouffe, C. 2011. En torno a lo político. México: Fondo de Cultura Económica.

Nadal, M-J. 1999. Le sexe/genre et la critique de la pensée binaire. Revue Recherches Sociologiques 30(3): 5-22.

Rancière, J. 1998. Aux bords du politique. Paris: Gallimard.

Revault d'Allonnes, M. 2006. El poder de los comienzos. Ensayo sobre la autoridad. Buenos Aires: Madrid. Tahon, M-B. 1999. Le micro-ondes, le privé et le domestique: rapports sociaux de sexe. Recherches sociologiques 30(3): 87-114.

Recibido el 30 Sep 2015

Aceptado el 15 Dic 2015 